\title{
El Profesionalismo. Un Código o Carta Constitucional para los médicos
}

\section{El Profesionalismo.Un Código o Carta Constitucional para los médicos}

En febrero del año 2002 se publicó simultáneamente en las revistas Lancet ${ }^{1}$ y Annals of Internal Medicine ${ }^{2}$ un documento del mayor interés. Es la propuesta de un nuevo Código o Carta Constitucional para la profesión médica, que propone los ideales a los que "todos los profesionales de la medicina pueden y debieran aspirar".

El documento es el producto de varios años de trabajo mancomunado de tres muy importante instituciones dedicadas a la medicina interna y en buena medida reguladoras de ésta: American Board of Internal Medicine, American College of Physicians y Federación Europea de Medicina Interna. No obstante ese origen, sus alcances llegan a todas las disciplinas médicas.

El Código consiste en una introducción o preámbulo de sus fundamentos, seguido de la propuesta de tres principios básicos y diez compromisos.

En el preámbulo señala que la profesión médica está amenazada, entre otros factores, por la explosión tecnológica, los cambios en las fuerzas del mercado, la organización y sistemas de dar atención médica, el bioterrorismo y la globalización. Como resultado de esto, a los médicos les resulta cada vez más difícil cumplir con sus responsabilidades con los pacientes y la sociedad.

También señala el preámbulo que el profesionalismo es la base de la relación entre la medicina y la sociedad y que él exige colocar los intereses de los enfermos por encima de los de los médicos. Así mismo incluye el concepto de que es parte del compromiso con los enfermos mantener niveles de competencia profesional así como proveer de consejos sanitarios expertos a la sociedad. Agrega que es esencial para el cumplimiento de estas normas, que el público tenga confianza en nosotros los médicos y eso depende de nuestra integridad individual y colectiva.

Hasta ahora los códigos de ética se habían referido a normas de conductas de los médicos para con sus pacientes, pero los cambios ocurri- dos han hecho necesario pensar en un código que involucre a los tres actores que actualmente interactúan en la acción médica: los médicos, los pacientes y la sociedad.

El Código o Carta Constitucional ha tenido un enorme impacto y gran acogida. Su página $\mathrm{Web}$ había recibido a mayo del 2003 algo más de 70 mil visitas, ha sido publicada por numerosas revistas de todas las especialidades médicas, ha sido traducido a diez idiomas y lo han suscrito 90 asociaciones profesionales o sociedades médicas de todas las disciplinas y continentes ${ }^{3}$. Actualmente se está pensando en desarrollar la fase II de este proyecto, abarcando la evaluación del impacto producido por el documento y explorar la oportunidad de definir los derechos a la salud y responsabilidades de los pacientes, médicos y sociedad $^{3}$.

El vocablo "profesionalismo", en la lengua castellana no refleja el contenido de esa Carta Constitucional, pero está aceptado universalmente, probablemente porque en inglés expresa mejor el contenido de este documento. En todo caso, esta Carta o Código establece principios y compromisos que son propios y exclusivos de la profesión de médico.

Todos los médicos debiéramos conocer el contenido de este Código y tratar de llevarlo a la práctica. Las revistas médicas, las sociedades de especialidades y las Escuelas de Medicina debieran participar en el esfuerzo de divulgar estas ideas.

Los siguientes son los principios y compromisos propuestos, traducidos al castellano por el Capítulo Chileno del American College of Physicians.

\section{Principios fundamentales}

Primacía del bienestar del paciente. Con altruismo se contribuye a la confianza, esencial 
para la relación médico-paciente. Las fuerzas del mercado, las presiones sociales y las exigencias administrativas no pueden vulnerar este principio.

Autonomía del paciente. Los médicos deben ser honestos con los pacientes y capacitarlos para que tomen decisiones informadas sobre su tratamiento.

Justicia social. Los médicos deben trabajar activamente para eliminar toda discriminación en los cuidados de salud, sea por razones étnicas o raciales, de género, socioeconómicas, religiosas o de cualquier otra categoría social.

\section{Conjunto de Compromisos}

Competencia profesional. Los médicos deben comprometerse a aprender toda la vida. Corporativamente, la profesión debe esforzarse por que todos sus miembros sean competentes.

Honestidad con los pacientes. Los médicos deben asegurarse de que los pacientes estén completa y honestamente informados antes de aceptar un tratamiento; deberán estar capacitados para decidir sobre el curso de la terapia. Los médicos también deben reconocer que, a veces, cometen errores que afectan a los pacientes. Si por ello resulta dañado un paciente, éste y su familia deben ser rápidamente informados, ya que lo contrario puede lesionar seriamente la confianza del paciente y de la sociedad, en los médicos y la medicina.

Confidencialidad con los pacientes. Satisfacer el compromiso de confidencialidad es más importante hoy que nunca antes, dado el amplio uso de sistemas de información electrónica para recopilar datos de los pacientes.

Mantener relaciones apropiadas con los pacientes. Los médicos nunca deberán aprovecharse sexualmente de sus pacientes, ni obtener con ellos ganancias financieras personales o utilizarlos con ningún otro propósito privado.
Mejorar la calidad de los cuidados. El médico debe trabajar con otros profesionales para reducir los errores, aumentar la seguridad de los pacientes, evitar el uso exagerado de los recursos y optimizar los cuidados de salud.

Mejorar el acceso a la atención de salud. Los médicos deben individual y colectivamente esforzarse por reducir las barreras para una atención de salud equitativa.

Justa distribución de recursos limitados. Los médicos deben comprometerse a trabajar con otros médicos, hospitales y financistas, para desarrollar guías de cuidados costo-efectivos. La responsabilidad profesional de los médicos para una apropiada asignación de recursos requiere evitar escrupulosamente efectuar exámenes y procedimientos superfluos.

Conocimiento científico. Los médicos tienen el deber de resguardar los estándares científicos, promover la investigación y crear nuevos conocimientos, asegurando su apropiada utilización.

Mantener la confianza manejando los conflictos de intereses. Los médicos tienen la obligación de reconocer, alertar al público en general y enfrentar los conflictos de intereses. Las relaciones entre la industria y los líderes de opinión debe ser transparente.

Responsabilidades profesionales. De los médicos se espera que participen en procesos de autorregulación, incluyendo la rectificación y la disciplina de los miembros que han faltado al cumplimiento de los estándares profesionales.

\section{Bibliografía}

1.- Medical Professionalism in the new millennium: a physicians' charter. Lancet 2002; 359: 520-2.

2.- Medical Professionalism in the new millennium: a physician charter. Ann Intern Med 2002; 136: 243-6.

3.- Blank L, Kimball H, McDonald W, Merino J. Medical professionalism in the new Millennium: a Physician Charter 15 Months Later. Ann Intern Med 2003; 138: 839-41. 